\title{
Studies of Phytoplankton Species and Photosynthetic Pigments in a Warm Core Eddy of the East Australian Current. II. A Note on Pigment Methodology
}

\author{
S. W. Jeffrey and G. M. Hallegraeff \\ CSIRO Division of Fisheries and Oceanography, P.O. Box 21, Cronulla, NSW 2230, Australia
}

\begin{abstract}
Photosynthetic pigments in a warm core eddy of the East Australian Current were studied by in vivo fluorometry, spectrophotometry and thin-layer chromatography. The Variosens in situ fluorometer gave only an approximate guide to the location and quantity of phytoplankton in the water column; spectrophotometric curve analysis revealed the presence of intact or detrital chlorophylls, and quantitative thin-layer chromatography showed that in some samples intact chlorophyll a accounted for only $50-70 \%$ of the total spectrophotometrically measured 'chlorophyll' In addition the full range of chlorophylls, carotenoids and chlorophyll degradation products was recorded from the chromatograms.
\end{abstract}

\section{INTRODUCTION}

In the previous paper (Jeffrey and Hallegraeff, 1980) the distribution of summer populations of phytoplankton at the centre and edges of a warm core eddy in the East Australian Current were summarized. In addition to species identifications, photosynthetic pigments were analysed by three methods - in situ fluorometry, spectrophotometry and thin-layer chromatography. The usefulness and limitations of these various techniques in studying field phytoplankton populations are briefly discussed below.

\section{MATERIALS AND METHODS}

The cruise track, sampling programme, preparation of water samples for pigment analysis and species identification, the use of the in situ Variosens fluorometer (Früngel and Koch, 1976), the spectrophotometric chlorophyll a analysis, and the thinlayer chromatographic procedures are as previously described (Jeffrey and Humphrey, 1975; Jeffrey and Hallegraeff, 1980, Jeffrey, in press).

For quantitative chromatographic analysis, the pigment spots were carefully scraped off the chromatograms, placed in centrifuge tubes or special elution tubes (Jeffrey, 1968) and eluted with about $0.5 \mathrm{ml}$ $100 \%$ acetone (chlorophylls) or ethanol (carotenoids). After $5 \mathrm{~min}$, the cellulose powder was removed by centrifugation, the pigment solution transferred to a calibrated $0.7 \mathrm{ml}$ capacity microcell, the volume accurately adjusted to a known volume, and the extinction measured using the 0.1 absorbance scale of the Cary 17 spectrophotometer. Pigment solutions containing only $0.2-0.7 \mu \mathrm{g}$ per $0.5 \mathrm{ml}$ solvent could thus be accurately measured. Extinction coefficients of pure pigments used for obtaining pigment concentrations are given in Jeffrey $(1968,1972)$, Jeffrey and Humphrey (1975) and Jeffrey et al. (1975).

\section{RESULTS AND DISCUSSION}

\section{Comparison of in Situ Fluorescence Profiles with Extracted Chlorophyll a}

The water column was always first profiled with the Variosens fluorometer to determine appropriate depths for discrete water sampling. Figure 1 shows the chlorophyll depth profiles by spectrophotometry of extracted chlorophyll $a$, compared with in vivo chlorophyll a fluorescence measured with the Variosens fluorometer. The best correspondence occurred 


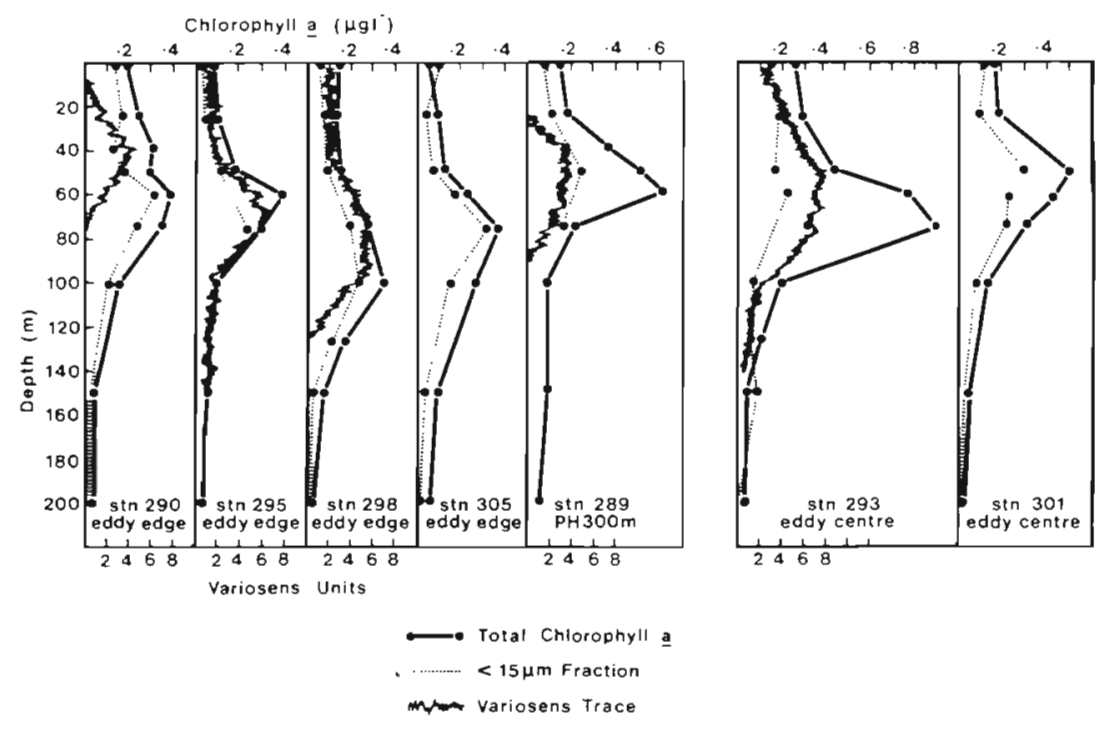

Fig. 1. Chlorophyll a profiles (total chlorophyll a and chlorophyll a from $<15 \mu \mathrm{m}$ fraction) compared with in vivo chlorophyll fluorescence (Variosens) at all phytoplankton sampling stations. Variosens Units as defined in Tranter et al. (1979)

at Stations 295 and 298 (eddy edge); less close correspondence was found at Stations 290 (eddy edge) and 293 (eddy centre) respectively

Figure 2 shows a comparison between Variosens profiles, chlorophyll $a$ and the depth distribution of the five dominant phytoplankton species categories, at one centre station (293) and one edge station (290). Both Nitzschia and Rhizosolenia showed a broad maximum from the surface down to about $75 \mathrm{~m}$ depth at the eddy centre (293), whereas the same species at the edge station (290) showed sharper subsurface maxima. The small flagellates (coccolithophorids, non-thecate dinoflagellates and green flagellates) were more uniformly distributed through the water column at the edges of the eddy, but at the centre stations the coccolithophorids and green flagellates showed sharper maxima with depth. At both stations the Variosens fluorescence profile corresponded more closely to the vertical distribution of Nitzschia than to any other species

The Variosens in situ fluorometer gave fluorescence profiles which were a valuable but only approximate guide to the location and quantity of chlorophyll (i.e. phytoplankton) in the water column. The depths of the maxima were sometimes out of phase by up to $25 \mathrm{~m}$ (Fig. 1). Wire angle differences could account only for small discrepancies (not more than about $10 \mathrm{~m}$ ). The fluorescence profiles correlated best with profiles of the larger diatoms, and less well with the flagellates (Fig. 2). It is possible that the instrument detects only a certain size range of alga with accuracy, and this range requires further definition. The Variosens fluorometer has also been evaluated against a Turner fluorometer measuring in vivo fluorescence (Herman and Denman,
1977) and against extracted chlorophyll a (Herman and Denman, 1977; Derenbach et al., 1979). Both authors recorded the necessity for frequent calibration.

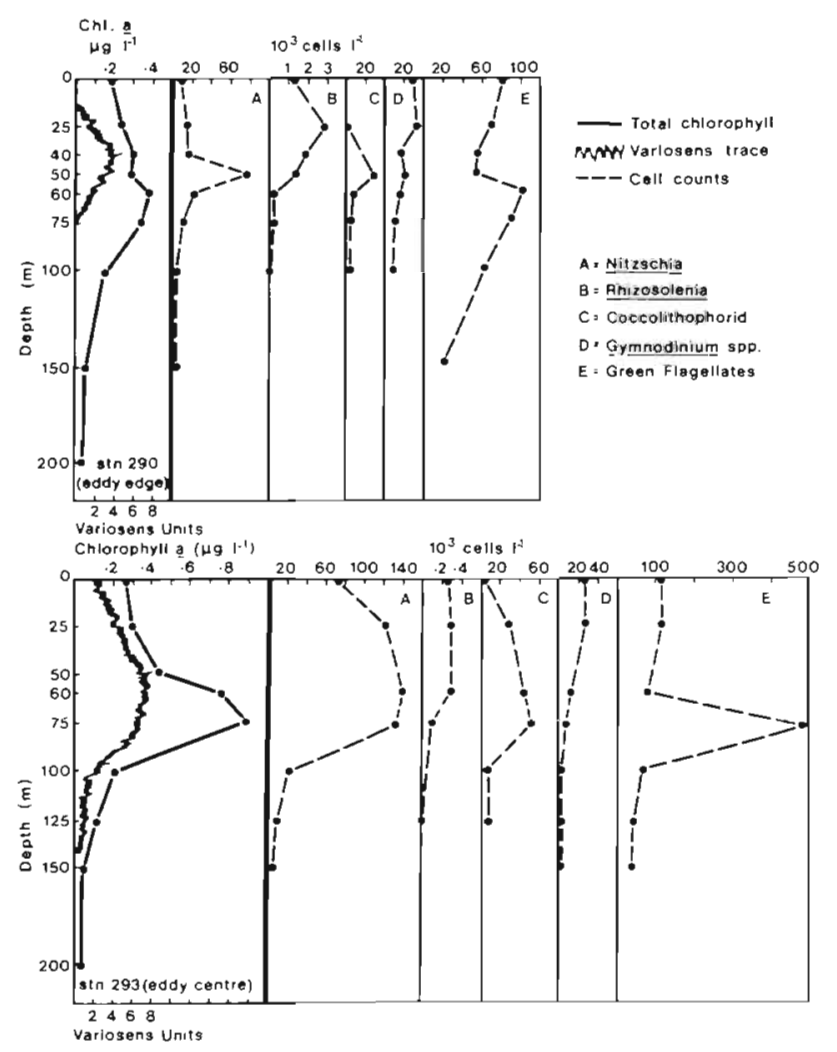

Fig. 2. Counts of dominant phytoplankton species compared with profiles of chlorophyll $a$ and in vivo fluorescence at an eddy edge station (290 above) and an eddy centre station (293 below) 


\section{Comparison of Spectrophotometric Pigment Analyses with Thin-Layer Chromatography}

\section{Qualitative Aspects}

The photosynthetic pigment profiles at the eddy centre Station (301) were evaluated both by thin-layer chromatography and by spectrophotometric curve analysis. Pigment chromatograms of discrete samples from surface waters to $1,000 \mathrm{~m}$ depth (Fig. 3) revealed chlorophylls $a$ and $c$, carotene and fucoxanthin (diatoms and coccolithophorids) at all depths down to $150 \mathrm{~m}$, chlorophyll $b$ and lutein (green algae) down to $75 \mathrm{~m}$, peridinin (dinoflagellates) at $50 \mathrm{~m}$, and astaxanthin (copepods) at $75 \mathrm{~m}$. An unidentified blue pigment, chromatographically identical to the acid rearrangement product of fucoxanthin, was found at both 50 and $100 \mathrm{~m}$. Its presence may indicate an acidification history for fucoxanthin after passage through the gut of planktonic animals. The only chlorophyll a degradation products at this station were pheophytin $a$ at 25 to $75 \mathrm{~m}$ and chlorophyllide a at $100 \mathrm{~m}$. Deep samples (below $150 \mathrm{~m}$ ) contained only chlorophyll $c_{\text {, }}$ carotene and detrital material at the origin of the chromatograms.

Absorption spectra of the phytoplankton pigment extracts taken from the same samples shown in Figure 3 revealed some interesting features. Figure 4 shows the non-quantitative family of curves from $0-1000 \mathrm{~m}$ using diethyl ether as solvent to enhance the spectral characteristics. Exact locations of peaks, inflections and minima of these curves are given in Table 1. The most obvious characteristic is the presence of a red maximum at all depths, even in the deepest samples which contained no chlorophyll a at all (Fig. 3). In these deep samples (200-1000 m) the red maxima were at $663-664 \mathrm{~nm}$, indicating the presence of chlorophyll a degradation products. (Chlorophyll $a$ in diethyl ether has its red maximum at $660 \mathrm{~nm}$, Table 1). These degradation products were probably located in the detrital 'origin' spot on the chromatograms (Fig. 3). The positions of the blue maxima of the pigment extracts (Fig. 4, Table 1) show these trends even more clearly. Samples from the upper $150 \mathrm{~m}$, which contained intact chlorophyll a (Fig. 3), and therefore came from living phytoplankton, had blue Soret maxima ranging from $427-430 \mathrm{~nm}$ (normal for the chlorophyll a Soret band, Table 1). However, in deep samples containing only detrital material the $430 \mathrm{~nm}$ (chlorophyll a) band had disappeared, and was replaced by one at $410-412 \mathrm{~nm}$ (similar to spectra of pheophytin a and pheophorbide a). At $150 \mathrm{~nm}$, where living cells and detrital material occurred, both peaks were apparent (427 and $412 \mathrm{~nm}$ ). A further distinction between living phytoplankton and detrital samples is the appearance of a well-

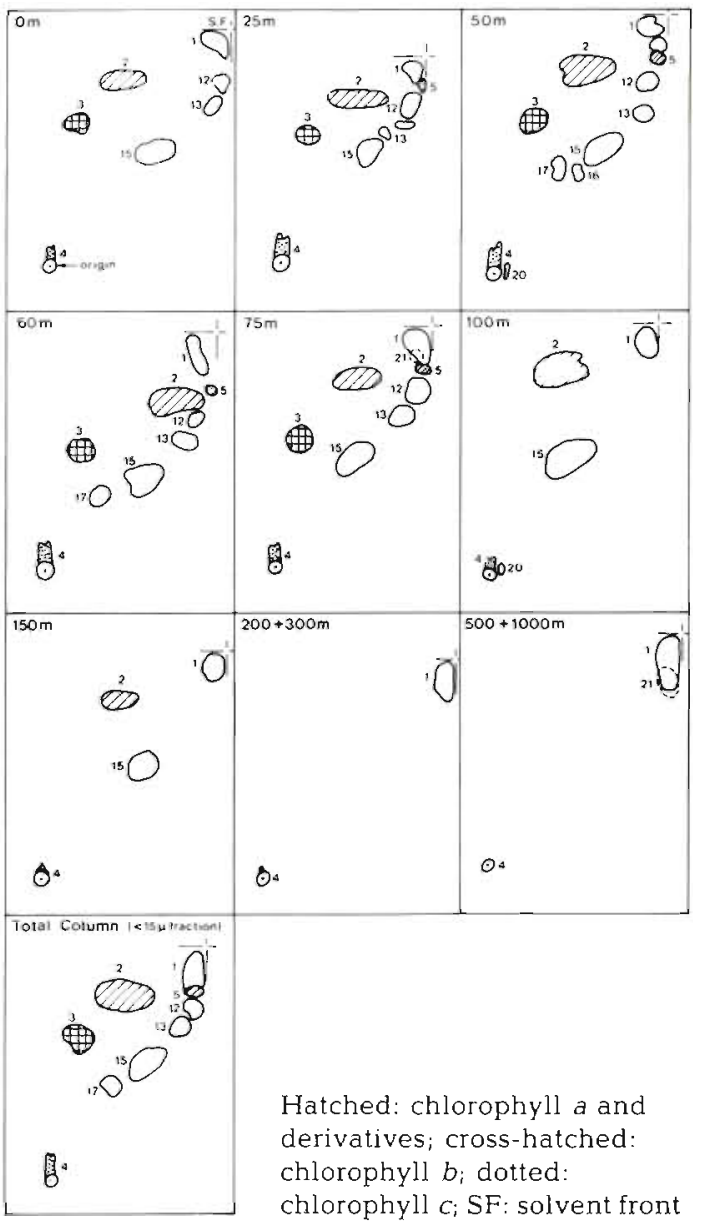

Fig. 3. Cellulose thin-layer chromatograms of photosynthetic pigments throughout water column $(0-1000 \mathrm{~m})$ at Station 301 (eddy centre). Solvent systems, 1st Dimension: $n$-propanol in light petroleum $\left(60-80^{\circ}\right), 2.5: 97.5(\mathrm{v} / \mathrm{v})$; 2nd Dimension: chloroform, light petroleum $\left(60-80^{\circ}\right)$, acetone, 25:75:0.5 (v/v/ v). 1: carotenes (yellow); 2 : chlorophyll a (blue-green); 3 : chlorophyll $b$ (olive green); 4 ; chlorophyll $c$ (light green); 5 : pheophytin a (grey); $6,7,8$ : unknown chlorophyll a derivatives (blue-green); 9, 10: chlorophyllide derivatives (bluegreen); 11, 12, 13, 14: yellow xanthophylls; 15: fucoxanthin (orange); 16: peridinin (brick-red); 17: neofucoxanthin (orange); 18: unknown xanthophyll (orange): 19: pheophorbide a (grey); 20: unknown pigment (blue); 21: unknown carotenoid (orange); 22, 23: chlorophyll derivatives (bluegreen)

marked blue minimum at $360-273 \mathrm{~nm}$ in the deep (150-1000 $\mathrm{m}$ ) samples. The absorption beyond this minimum rose steeply into the U. V. region. This feature was also rather surprisingly found in the surface $(0 \mathrm{~m})$ sample, which not only showed a rather prominent 'origin spot' on the chromatogram (Fig. 3), but contained many disintegrating and senescent Nitzschia cells. These steeply rising detrital curves in the U. V. region are reminiscent of curves of pigment extracts of Antarctic sediments, some of which contain 
Table 1. Spectral characteristics of pigment extracts of phytoplankton from 0-1000 m depth (Station 301) compared to pigment extracts of a diatom (Stephanopyxis turnis), a green flagellate (Tetraselmis suecica), a dinoflagellate (Amphidinium carterae), and pure chiorophylls $a, b, c_{1}$ and $c_{2}$. Solvent diethyl ether $\sim$ indicates an inflection

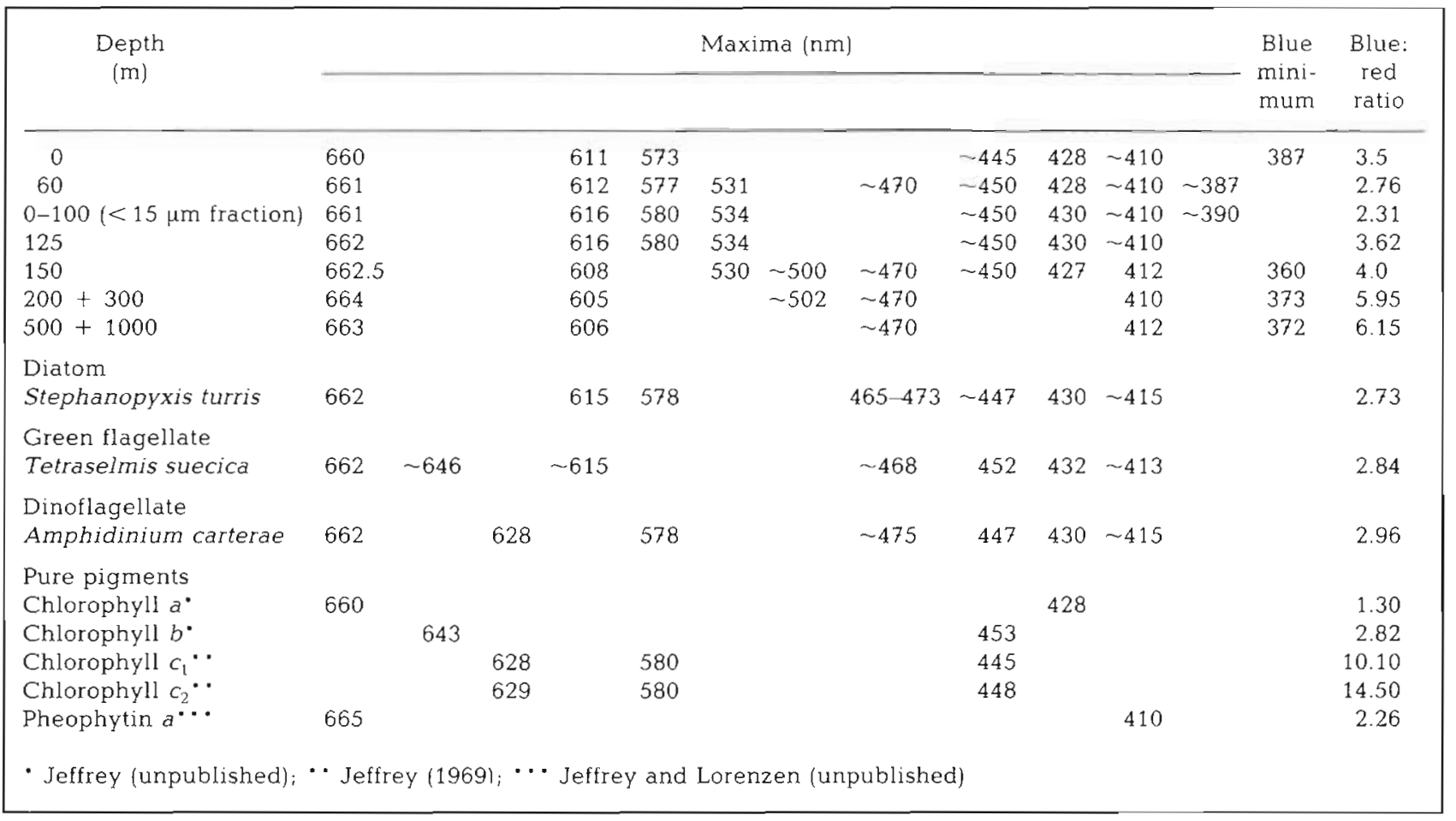

no red band at all (Jeffrey and Holm-Hansen, unpublished).

This U. V. absorbance has been recorded previously for acetone extracts of particulate material from 300-1000 $\mathrm{m}$ depths in the Sargasso Sea (Yentsch and Ryther, 1959), and extracts of lake sediments (Gorham, 1960).

The identitiy of minor peaks and inflections in field samples due to accessory chlorophylls and carotenoids may be compared with absorption spectra of ether extracts of pigments from a cultured diatom Stephanopyxis turris, a green flagellate Tetraselmis suecica and a dinoflagellate Amphidinium carterae (Fig. 5), and with absorption maxima of ether solutions of pure chlorophylls $a, b, c_{1}$ and $c_{2}$ (Table 1). For example, in the Tetraselmis curve the $646 \mathrm{~nm}$ inflection is due to chlorophyll $b$, and the 452 and the $430 \mathrm{~nm}$ peaks, the blue (Soret) absorption bands of chlorophylls $b$ and $a$, respectively. In the Stephanopyxis curve the inflection at $465-473 \mathrm{~nm}$ is mainly fucoxanthin, and the inflection at $447 \mathrm{~nm}$ and the peak at $430 \mathrm{~nm}$ are the blue maxima of chlorophyll $c$ and $a$, respectively. In the Amphidinium curve, the small red maximum of chlorophyll $c$ is revealed at $628 \mathrm{~nm}$, the presence of peridinin by the inflection at $475 \mathrm{~nm}$, and the blue maxima of chlorophylls $c$ and $a$ at 447 and $430 \mathrm{~nm}$, respectively. Peaks and inflections in these areas in the phytoplankton curves (Fig. 4) may be interpreted similarly, and the identity of the pigments present confirmed from the chromatograms.

The ratio of blue to red bands taken at the maxima (Table 1) show further characteristics of phytoplankton pigments. Pure chlorophyll a in diethyl ether has a blue:red ratio of $1 \cdot 30$. The presence of carotenoids absorbing in the blue-green region in extracts of diatoms, green flagellates and dinoflagellates, in addition to chlorophylls $a$ and $c_{\text {, }}$ raises this ratio to 2.73-2.96. Natural phytoplankton samples containing mostly living cells $(0-125 \mathrm{~m})$ showed blue:red ratios of 2.31-3.62. With more detritus and less living cells in the water column these ratios rose to $4.0(150 \mathrm{~m}), 5.95$ $(200+300 \mathrm{~m})$ and $6.15(500+1000 \mathrm{~m})$. Thus simple inspection of pigment curves in diethyl ether can give useful information concerning their phytoplankton or detrital origin.

\section{Quantitative Aspects}

Five samples, collected at the Variosens fluorescence maxima were pooled and used for quantitative pigment analyses. Chromatograms of these pooled samples are shown in Figure 6A (Stations $300+302$, eddy centre) and Figure 6B (Stations $291+294+299$, midway between eddy centre and eddy edge). Quan- 


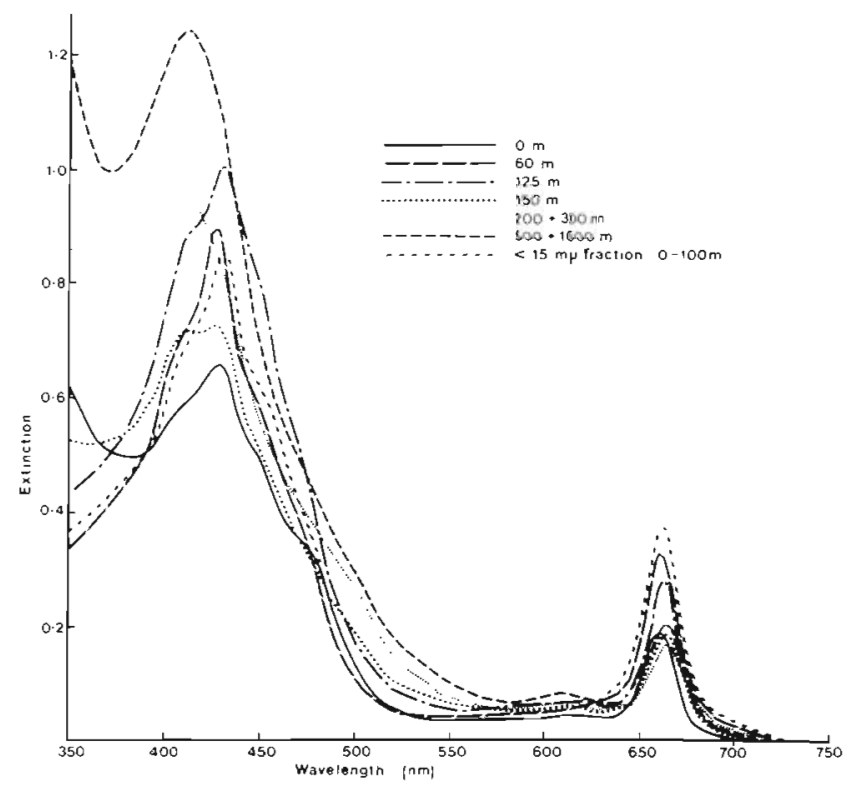

Fig. 4. Absorption spectra of phytoplankton pigments from 0-1000 $\mathrm{m}$ at Station 301. These spectra display characteristics associated with the presence of living phytoplankton or detrital material; no quantitative significance is intended. Solvent: diethyl ether

titative analyses of the eluted pigments are given in Table 2. Because much more pigment was available for analysis in these pooled samples, all chlorophyll breakdown products were more clearly identified. These were pheophytin a (Fraction 5), chlorophyllide a (9), pheophorbide a (19), and the unidentified deriva- tives $(6,7,8,10,22$ and 23$)$. The quantitative analyses in Table 2 show that intact chlorophyll a in these pooled samples amounted to only $50-70 \%$ of the total material absorbing at $664 \mathrm{~nm}$. The unidentified bluegreen chlorophyll a derivatives amounted to $20-24 \%$ of the total 'chlorophyll $a$ ', the 'origin' material accounted for $8 \%$, and pheophytin $a$, pheophorbide $a$, and chlorophyllide a together reached $19 \%$ of the total in these pooled samples. In simple spectrophotometric and fluorescence methods all these derivatives would be measured as chlorophyll a.

The presence of these products on chromatograms provides clues to the physiological state of phytoplankton (Jeffrey, 1974; Lorenzen and Jeffrey, in press). Pheophorbide $a$, a marker of zooplankton grazing (Jeffrey, 1974; Shuman and Lorenzen, 1975), and

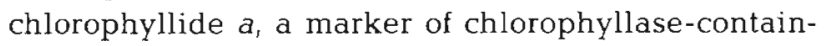
ing diatoms (Jeffrey, 1974), were previously found in Australian coastal waters. However, these compounds were only detected occasionally in the present work. Instead, pheophytin a was the most common degradation product encountered. Its presence was not entirely due to storage artefacts (unpublished experiments), and it may have originated from faecal material from salps and small copepods (Hallegraeff, in press) which were abundant at some eddy stations (Heron, pers. comm.). Neveux (1975) has also recognised pheophytin a (from chromatograms) as a major chlorophyll degradation product in Mediterranean and coastal Atlantic waters.

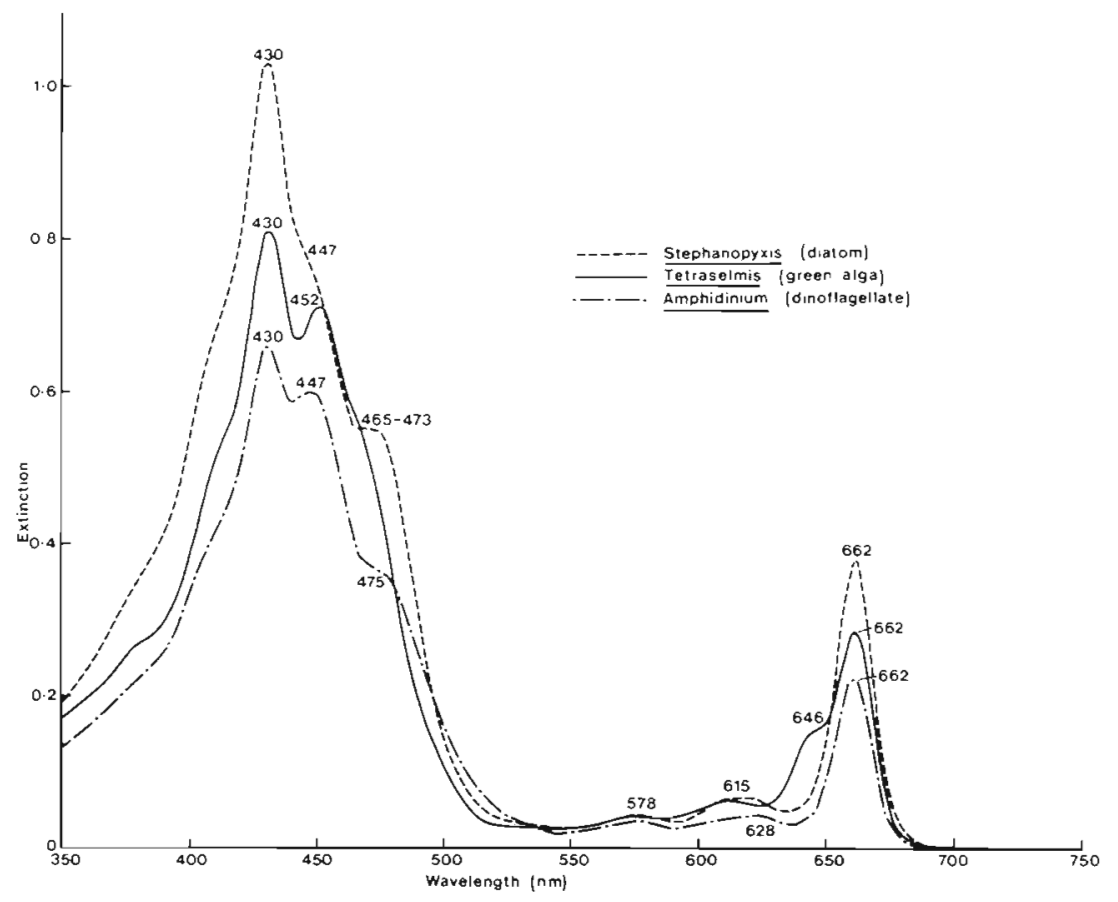

Fig. 5. Pigment absorption spectra of diatom Stephanopyxis turris, green flagellate Tetraselmis suecica and dinoflagellate Amphidinium carterae. Solvent: diethyl ether 
Table 2. Relative proportions of pigment fractions eluted quantitatively from cellulose thin-layer chromatograms for two grouped sets of $10 \mathrm{l}$ samples collected at Variosens maxima. A: Stations $300+302$ (eddy centre), 201 sample B: Stations $291+294+299$ (midway stations), 30 l sample

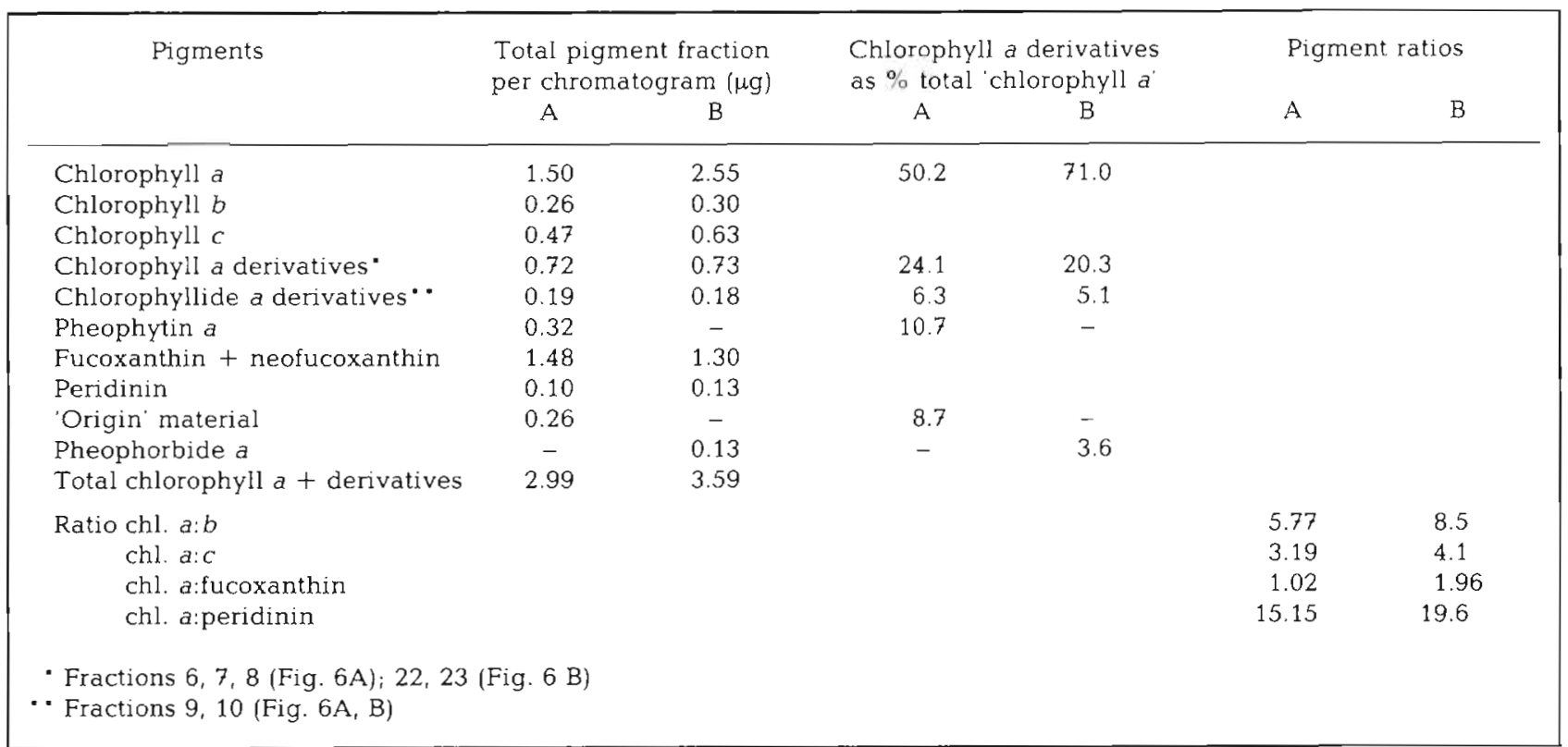

Table 3. Concentrations and ratios of chlorophylls $a, b$ and $c$ at selected stations, using trichromatic spectrophotometry

\begin{tabular}{|c|c|c|c|c|c|c|}
\hline \multirow[t]{2}{*}{ Station } & \multirow[t]{2}{*}{$\begin{array}{c}\text { Depth } \\
(\mathrm{m})\end{array}$} & \multicolumn{3}{|c|}{$\begin{array}{c}\text { Chlorophylls } \\
\left.(\mu \mathrm{g})^{-1}\right)\end{array}$} & \multirow[b]{2}{*}{$a: b$} & \multirow[b]{2}{*}{$a: c$} \\
\hline & & $a$ & $b$ & c & & \\
\hline \multirow{5}{*}{$\begin{array}{c}301 \\
\text { (Eddy centre) }\end{array}$} & 0 & 0.14 & 0.03 & 0.04 & 5.36 & 3.19 \\
\hline & 25 & 0.17 & 0.02 & 0.04 & 7.00 & 4.45 \\
\hline & 50 & 0.49 & 0.08 & 0.13 & 6.49 & 3.72 \\
\hline & 60 & 0.43 & 0.08 & 0.12 & 5.49 & 3.52 \\
\hline & 75 & 0.30 & 0.06 & 0.08 & 5.42 & 3.82 \\
\hline \multirow{4}{*}{$\begin{array}{c}305 \\
\text { (Eddy edge) }\end{array}$} & 50 & 0.10 & 0.007 & 0.03 & 14.30 & 3.90 \\
\hline & 60 & 0.21 & 0.046 & 0.054 & 4.56 & 3.89 \\
\hline & 75 & 0.36 & 0.13 & 0.008 & 2.73 & 4.43 \\
\hline & 100 & 0.25 & 0.11 & 0.07 & 2.26 & 3.49 \\
\hline
\end{tabular}

Several unidentified blue-green chlorophyll a derivatives were abundant on chromatograms of eddy samples (Fig. 6). These have also been observed at inshore stations of the East Australian Current (Jeffrey, 1974; Hallegraeff, in press), and in senescent bluegreen light diatom cultures (Jeffrey, unpublished). Their absorption spectra, chromatographic properties and possible identity will be discussed elsewhere.

\section{Pigment Ratios}

Ratios of chlorophylls $a: b$ and $a: c$ calculated from trichromatic equations (Jeffrey and Humphrey, 1975) for two stations are given in Table 3 . These ranged from 2.26 to 7.00 (excluding one very low $b$ sample) and 3.19 to 4.45 , respectively. Pigment ratios for other stations calculated from quantitative thin-layer chromatography (Table 2) gave similar values: chlorophyll $a: b, 5.77$ and 8.5; chlorophyll $a: c, 3.19$ and 4.1: chlorophyll a:fucoxanthin, 1.02 and 1.96; and chlorophyll a:peridinin, 15.15 and 19.6. The low content of peridinin was surprising, considering the abundance of the small dinoflagellates, and suggests that many of the dinoflagellates observed microscopically must have been colourless, non-photosynthetic forms.

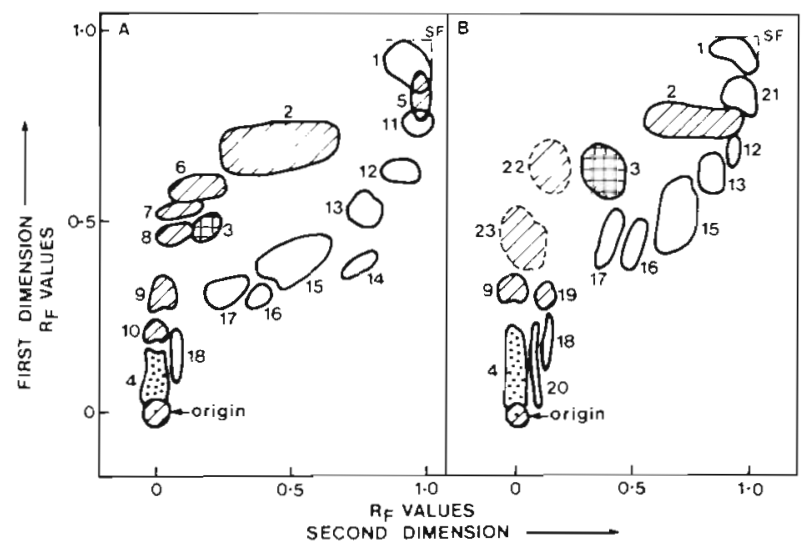

Fig. 6. Cellulose thin-layer chromatograms of samples. A: Variosens maximum at Stations $300+302$ combined (eddy centre); B: Variosens maximum at Stations 291, $297+299$ combined (midway between eddy centre and eddy edge). Solvent systems and identity of pigment fractions as for Figure 3. SF: solvent front 


\section{CONCLUSIONS}

In situ fluorometry, spectrophotometry and thinlayer chromatography gave increasing detail of pigments in phytoplankton samples. In situ fluorescence located the phytoplankton populations in the water column, spectrophotometry gave accurate data on chlorophyll a concentrations providing there was no interference from chlorophyll degradation products, curve analysis detected the presence of detrital chlorophylls, and thin-layer chromatography revealed the full pigment complement and allowed accurate quantitative analysis of all pigment fractions.

Acknowledgements. G. M. Hallegraeff wishes to thank the Netherlands Organization for the Advancement of Pure Research (Z. W. O.) for Stipend L84-161 (from March to December, 1978), and the CSIRO Division of Fisheries and Oceanography for a visiting scientist position (from January 1979 to June 1980). We thank Mr D. Vaudrey for the Variosens fluorescence profiles.

\section{LITERATURE CITED}

Derenbach, J. B., Astheimer, H., Hansen, H. P., Leach, H. (1979). Vertical microscale distribution of phytoplankton in relation to the thermocline. Mar. Ecol. Prog. Ser. 1: $187-193$

Früngel, F., Koch, C. (1976). Practical experience with the Variosens equipment in measuring chlorophyll concentrations and fluorescent tracer substances, like rhodamine, fluorescein, and some new substances. IEEE J. Oceanogr. Engng. OE-1: 21-32

Gorham, E. (1960). Chlorophyll derivatives in surface muds from English lakes. Limnol. Oceanogr. 5: 29--33

Hallegraeff, G. M. (in press). A seasonal study of phytoplankton pigments and species at a coastal station off Sydney: the importance of diatoms and the nanoplankton. Mar. Biol.
Herman, A. W., Denman, K. L. (1977). Rapid underway profiling of chlorophyll with an in situ fluorometer mounted on a 'Batfish' vehicle. Deep Sea Res. 24: 385-397

Jeffrey, S. W. (1968). Quantitative thin-layer chromatography of chlorophylls and carotenoids from marine algae. Biochim. biophys. Acta 162: 271-285

Jeffrey, S. W (1969). Properties of two spectrally distinct components in chlorophyll c preparations. Biochim. biophys. Acta 177: 456-467

Jeffrey, S. W (1972). Preparation and some properties of chlorophylls $c_{1}$ and $c_{1}$ from marine algae. Biochim. biophys. Acta 279: 15-33

Jeffrey, S. W. (1974). Profiles of photosynthetic pigments in the ocean using thin-layer chromatography. Mar. Biol. 26: $101-110$

Jeffrey, S. W. (in press). An improved thin-layer chromatography technique for marine phytoplankton pigments. Limnol. Oceanogr.

Jeffrey, S. W., Hallegraeff, G. M. ( 1980). Studies of phytoplankton species and photosynthetic pigments in a warm core eddy of the East Australian Current. I. Summer populations. Mar. Ecol. Prog. Ser. 3: 285-294

Jeffrey, S. W., Humphrey, G. F. (1975). New spectrophotometric equations for determining chlorophylls $a, b, c_{1}$ and $c_{2}$ in higher plants, algae and natural phytoplankton. Biochem. Physiol. Pfl. 167: 191-194

Jeffrey, S. W., Sielicki, M., Haxo, F. T. (1975). Chloroplast pigment patterns in dinoflagellates. J. Phycol. 11: 374-384

Lorenzen, C. J., Jeffrey, S. W. (in press). The determination of chlorophyll in seawater. SCOR-UNESCO Tech. Pap. Mar. Sci.

Neveux, J. (1975). Analyse chromatographique des pigments du phytoplancton en Méditerranée nord-occidentale et près des côtes atlantiques marocains. Int. Revue ges. Hydrobiol. 60: 675-690

Shuman, F. R., Lorenzen, C. J. (1975). Quantitative degradation of chlorophyll by a marine herbivore. Limnol. Oceanogr. 20: 580-586

Tranter, D. J., Parker, R. R., Vaudrey, D. J. (1979). In vivo chlorophyll a fluorescence in the vicinity of warm-core eddies off the coast of N. S. W. 1. September 1978. Aust. CSIRO Div. Fish. Oceanogr. Rep. 105: 1-29

Yentsch, C. S., Ryther, J. H. (1959). Absorption curves of acetone extracts of deep water particulate matter. Deep Sea Res. 6: 72-74 